\title{
THE AUSTRALIAN LONGITUDINAL STUDY ON WOMEN'S HEALTH: STUDY DESIGN AND SAMPLE
}

Wendy J Brown, Annette J Dobson, and the ALSWH Research Team

Research Institute for Gender and Health

University of Newcastle

This article describes the Women's Health Australia (WHA) project, formerly known as the Australian Longitudinal Study on Women's Health (ALSWH), which commenced in June 1995 as a result of initiatives arising from the National Women's Health Policy. ${ }^{1}$ In contrast to several overseas longitudinal studies, which have focused on women from specific geographical areas (for example, the Iowa Women's Health Study), ${ }^{2}$ or occupation groups (for example, the Nurses Health Study), ${ }^{3}$ this study was designed to explore factors that promote or reduce health in women who are broadly representative of the whole Australian population. An overall goal of the project is to clarify cause-effect relationships between women's health and a range of biological, psychological, social and lifestyle factors (see Figure 1). The WHA project is committed to focusing on a social view of health and to being relevant to the formulation of health policy. It involves the collection of quantitative and qualitative data, as well as record linkage with other sources of data. The research team of more than 20 investigators, mostly women, encompasses a wide range of disciplinary perspectives including sociology, epidemiology, psychology, medicine, nutrition, demography and statistics.

The study involves three main cohorts of women selected on the basis of age:

- young (aged 18-23 years at the time of baseline data collection in 1996)

- mid-age (45-50 years)

- older women (70-75 years).

The studies of these groups are managed by researchers from the University of Newcastle. There are also several smaller special cohorts of Aboriginal and Torres Strait Islander women, which are managed by researchers from the University of Queensland.

The Medicare database was used by the Health Insurance Commission (HIC) as the sampling frame to select the women to receive the initial invitation to participate in the main cohort studies. Since 70 per cent of Australian women live in major (coastal) cities, there was deliberate over-sampling of women living in rural and remote areas to ensure their adequate inclusion. Statutory restrictions on the use of the HIC database required that the identities of the selected women remain unknown to researchers until they consented to participate or voluntarily contacted the research team. Recruitment was therefore limited entirely to materials mailed from the HIC, without the advantage of usual methods to encourage participation (for example, by telephone contact).
More than 41,000 women (14,792 young women, 14,200 mid-age women and 12,624 older women) responded to the baseline surveys for the main cohorts in 1996. Due to uncertainties regarding the accuracy of the Medicare database, response rates cannot be exactly specified. It is estimated that 41-42 per cent, 53-56 per cent and 37-40 per cent of the young, mid-age and older women respectively responded to the initial invitation to participate. ${ }^{4}$

In light of these response rates, it is important to assess any response bias in determining the generalisability of study findings. A demographic comparison of respondents and non-respondents was impossible because privacy guidelines prevented access to information concerning women who were selected to receive an invitation but failed to respond. We were able, however, to assess the degree to which participants demographically represent the general population of Australian women through comparison with 1996 census data. The study cohorts include more women in married or de facto relationships than the general population, particularly in the younger group. This reflects the over-representation of rural and remote women, who tend to marry earlier than their urban counterparts. In the mid-age cohort more women are employed, while women in the workforce are underrepresented in the younger cohort. This suggests there may be an over-representation of full-time students in the young cohort. While there is a degree of overrepresentation of women born in Australia and other English-speaking countries in all three main cohorts, women from Europe and Asia are well represented. The proportion of Aboriginal and Torres Strait Islander women in each cohort is also similar to that in the census data,

\section{FIGURE 1}

DIAGRAMMATIC REPRESENTATION OFTHE OVERARCHING GOAL OF THE STUDY:TO DETERMINETHE FACTORSTHAT DETERMINE GOOD HEALTH FOR WOMEN.

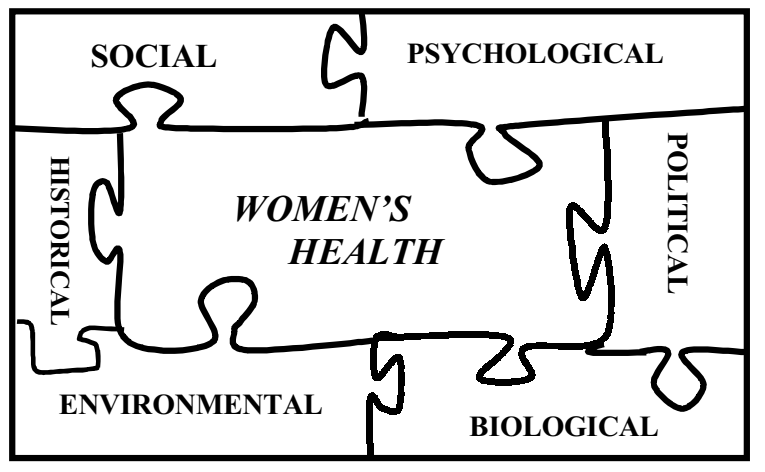


SURVEY PLAN FOR THE THREE MAIN COHORTS OF WOMEN FOR TWENTY YEARS. *

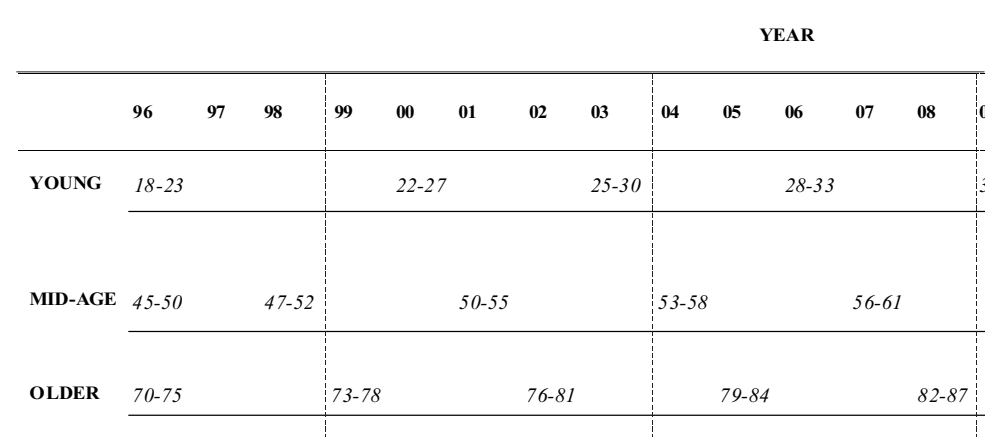

${ }^{*}$ Figures in italics indicate the age of the women in each main cohort at the time of each planned follow-up survey.

Dashed vertical lines indicate past, current and proposed funding periods.

although Aboriginal women from remote areas are underrepresented. ${ }^{4}$

Baseline surveys were conducted for all three cohorts in 1996, and plans for the follow-up surveys of each main cohort over a 20-year period are displayed in Figure 2.5 The first follow-up surveys of the mid-age and older cohorts in 1998 and 1999 achieved response rates exceeding 90 per cent. Development of the survey for the first followup of the young cohort is currently underway.

\section{REFERENCES}

1. Brown WJ, Bryson L, Byles JE, Dobson AJ, Manderson L, Schofield M, Williams G. Women's Health Australia: establishment of the Australian Longitudinal Study on Women's Health. J Women's Health 1996; 5(5): 467-572.
2. Steinmetz KA, Kushi LA, Bostick RM, Folsom AR, Potter JD. Vegetables, fruit and colon cancer in the Iowa Women's Health Study. Am J Epidemiol 1994; 139: 1-15.

3. Barton J, Bain C, Hennekens CH, Rosner B, Belanger C, Roth A, Speizer FE. Characteristics of respondents and nonrespondents to a mailed questionnaire. Am J Public Health 1980; 70: 823-825.

4. Brown WJ, Bryson L, Byles JE, Dobson AJ, Lee C, Mishra G, Schofield M. Women's Health Australia: recruitment for a national longitudinal cohort study. Women and Health 1998; 28(1): 23-40.

5. Brown WJ, Dobson AJ, Bryson L, Byles JE. Women's Health Australia: update on the progress of the main cohort studies. $J$ Women's Health and Gender Based Medicine 1999: 8(5) 681-688. it:

\section{THE AUSTRALIAN LONGITUDINAL STUDY ON WOMEN'S HEALTH: SELECTED EARLY FINDINGS AND FUTURE RESEARCH OBJECTIVES FOR THE MAIN COHORTS}

Wendy J Brown, Annette J Dobson, and the ALSWH Research Team

Research Institute for Gender and Health

University of Newcastle

\section{INTRODUCTION}

Women's Health Australia is a major study by international standards, with the potential to make a significant contribution to the investigation of factors that enhance or inhibit good health for women. The Australian Government, through the Commonwealth Department of Health and Aged Care and the National Health and Medical Research Council, has made a commitment to the research and to using the findings to improve the health care system's response to women's needs. Comparisons between the three age cohorts described in the previous article are of particular interest in establishing whether the nature and extent of health problems represent sociallyconstructed generational differences, or reflect the biological ageing process of women. The longitudinal design provides a unique opportunity to explore causal relationships between the use of health care services, life events, weight and exercise, violence, use of time (paid and unpaid work and leisure), and long-term health and well being. Our primary aim is to ensure that the findings are translated into policies and practices that are relevant, and reflect the social and cultural diversity of these three 